\title{
The impact of selection on milk production on the lactoferrin content of milk in Irish Holstein- Friesians
}

S Mc Parland ${ }^{1}$, L Giblin ${ }^{2}$, R.F. Veerkamp ${ }^{3}$, D.P. Berry ${ }^{1}$

${ }^{1}$ Teagasc Moorepark Dairy Production Research Centre, Fermoy, Co Cork, Ireland

${ }^{2}$ Teagasc Moorepark Food Research Centre, Fermoy, Co Cork, Ireland

${ }^{3}$ Animal Breeding and Genomics Centre, Animal Sciences Group, PO Box 65, 8200 AB, Lelystad, Netherlands

Email: sinead.mcparland@teagasc.ie

Introduction Bovine lactoferrin is an important innate immune protein with a wide range of host defence functions including anti-microbial and anti-viral properties. This bioactive is found naturally in bovine milk and is considered to confer health benefits to both consumer and dairy cow. Currently, the Irish total merit index, the Economic Breeding Index (EBI) does not include the lactoferrin content of milk. The objective of this study was to determine what associations, if any exist between the lactoferrin content of milk and other milk constituents and to make inferences into the impact of selection on milk production on milk lactoferrin content.

Material and methods Milk samples ( $\mathrm{n}=865)$ from 620 Holstein-Friesian cows stationed at five Teagasc research stations in the south of Ireland were obtained during routine weekly milk recording between May and October 2009. Experiments in operation during this time investigated the impact of a) level of herbage mass offered, b) grazing stocking rate, c) feeding system d) autumn calving and e) different concentrate feeding levels and grazing stocking rate on overall animal performance. All animals were on a basal grass based diet and included spring and autumn calving cows. Lactoferrin content (mg/L milk) for all milk samples was determined using the Bovine Lactoferrin ELISA quantification kit (Bethyl Laboratories) at Enfer Laboratories, Naas, Co. Kildare. Milk composition data corresponding to the milk samples analysed for lactoferrin content was also obtained. Only test-day records between 5 and 305 days in milk were retained. From the remaining records, only a single lactoferrin result per cow was retained resulting in 580 records. Milk lactoferrin content was positively skewed and was therefore transformed using the logarithm to the base ten. Phenotypic and genetic (co)variance between lactoferrin content and milk production were estimated using an animal linear mixed model in ASREML (Gilmour et al., 2009). Fixed effects included in all models were cow parity, experimental treatment, stage of lactation and milking time (AM or PM).

Results The heritability of lactoferrin content was 0.30 (standard error $=0.10$ ). The coefficient of genetic variation was $6.5 \%$. The genetic correlations between lactoferrin and milk yield traits were positive or close to zero, while the phenotypic correlation between lactoferrin content and yield traits was negative. Lactoferrin was positively correlated with protein percent and casein content and negatively correlated with lactose percent, urea and SCS. However, the size of the standard errors of the genetic correlations were large and only the genetic correlations between lactoferrin content and protein percent, and lactoferrin content and casein $(\mathrm{kg})$ differed $(\mathrm{P}<0.05)$ from zero.

Table 1 Genetic and phenotypic correlations ${ }^{\star}$ between milk lactoferrin content and milk constituents

\begin{tabular}{lll}
\hline \hline & Genetic & Phenotypic \\
\hline Milk (kg) & $0.07(0.246)$ & $-0.16(0.046)^{* * *}$ \\
Fat $(\mathrm{kg})$ & $0.24(0.277)$ & $-0.11(0.045)^{*}$ \\
Protein $(\mathrm{kg})$ & $0.30(0.247)$ & $-0.06(0.046)$ \\
Lactose $(\mathrm{kg})$ & $0.00(0.260)$ & $-0.20(0.044)^{* * *}$ \\
Fat Percent & $0.21(0.305)$ & $0.01(0.045)$ \\
Protein Percent & $0.43(0.191)^{*}$ & $0.26(0.043)^{* * *}$ \\
Lactose Percent & $-0.37(0.237)$ & $-0.30(0.042)^{* * *}$ \\
Urea $(\mathrm{kg})$ & $-0.31(0.308)$ & $-0.09(0.044)$ \\
Casein $(\mathrm{kg})$ & $0.38(0.196)^{*}$ & $0.21(0.045)^{* * *}$ \\
SCS & $-0.36(0.326)$ & $0.29(0.043)^{* * *}$ \\
\hline \multirow{*}{*}{$\mathrm{P}<0.05, * * * \mathrm{p}<0.001$} &
\end{tabular}

Conclusion The existence of a moderate heritability estimate coupled with significant genetic variation clearly indicate that genetic selection for lactoferrin content is possible. These results indicate that genetic selection for milk yield will not have a correlated response on the lactoferrin content of milk. However, more data and a larger number of animals are required to obtain more precise estimates of the genetic correlations.

Acknowledgements The RobustMilk project is financially supported by the European Commission under the Seventh Research Framework Programme, Grant Agreement KBBE-211708. The content of this paper is the sole responsibility of the authors, and it does not necessarily represent the views of the Commission or its services. The authors gratefully acknowledge the assistance of Dr. Fiona O'Halloran.

\section{References}

Gilmour, A. R., B. R. Cullis, S. J. Welham, and R. Thompson. 2009. ASReml reference manual, $2^{\text {nd }}$ edition. 